\title{
KNOWLEDGE, ATTITUDE AND PRACTICE OF BREAST CANCER SCREENING AMONG HEALTH SCIENCE STUDENTS IN SHAHREKORD CITY, IRAN
}

\author{
Nimetcan Mehmet ${ }^{1}$, Azam Rahimi ${ }^{2}$, Abdul-Ghaffar Donkor ${ }^{1}$, Alabed Ali A. Alabed ${ }^{3}$ and *Masoud Lotfizadeh ${ }^{4}$ \\ ${ }_{1}$ Department of Public Health, Faculty of Medicine, Ankara Yildirim Beyazit University, Turkey \\ 2 Iran, social security organization \\ ${ }^{3}$ Community Medicine Department, Faculty of Medicine, Lincoln University College, Malaysia \\ ${ }^{4}$ Social Determinants of Health Research Center, Shahrekord University of Medical Sciences, Shahrekord, Iran
}

${ }^{*}$ Corresponding Author: Masoud Lotfizadeh

E-mail: masoud_lotfizadeh@yahoo.com

\begin{abstract}
The aim of this study is to assess the knowledge, attitude and practices of breast cancer among health science students in Shahrekord city, Iran. A cross- sectional study was conducted in 2017-2018 academic year among 334 health science students in Shahrekord University of Medical Sciences. Data was collected using self-administered structured questionnaire. The total score for knowledge was 18. Any respondent who had more than 9 was considered as having good knowledge and below 9 as having poor knowledge. The total score for attitude was 7. Any score more than 4 was considered as good attitude and score less than 4 was considered as bad attitude. The mean age of the respondents was $21.21 \pm 1.19$ years. Most of the respondents aged 18 to 21 years. The knowledge level was significantly different by age group $(P=0.002)$, department $(P=0.000)$ and those who attended training course $(P=0.000)$. Those who perform BSE (Breast Self-Examination) had higher knowledge score about breast cancer than those who do not perform BSE ( $P=0.000)$. The participants' attitude was not significantly different by age group, department, family history of cancer and attending of training courses ( $p>$ 0.05). The breast self-examination practice was significantly different by age group $(P=0.002)$, department $(P=0.000)$ and those who attended training course $(P=0.000)$. About half of the respondents had good knowledge on breast cancer. However, more than half of the participants had negative attitude towards breast cancer. For example, less than half of the respondents performed BSE and none of the respondents has performed CBE (Clinical Breast Examination) or mammogram before.
\end{abstract}

Key words: Breast Cancer, Health science students, Knowledge, Attitude, Practice.

\section{INTRODUCTION}

Breast cancer is the most frequent cancer among women, affecting 2.1 million women each year. It also causes the greatest number of cancer-related deaths among women. In 2018, it is estimated that 627,000 women died from breast cancer - about 15\% of all cancer deaths among women. While breast cancer rates are higher among women in more developed regions, rates are increasing in nearly every region globally ${ }^{1}$. The age-standardized incidence in North America is the highest, at 99.4 per 100,000, while the lowest is in central Africa where it is 16.5 per $100,000^{2}$. According to the Iranian Cancer Registry Report in 2009, there were 8,616 women diagnosed with breast cancer with age standardized mortality rate (ASR) of 28.1 per 100,000 females $^{3}$. In Iran, Breast Cancer is the first among cancers diagnosed in females consisting $24.4 \%$ of all cancers with ASR of 23.1 per 100,000 . It is also the fifth most common cause of deaths related to cancers ${ }^{4,5}$.

In order to improve breast cancer prognosis and survival, early detection is critical. There are two early detection strategies for breast cancer: early diagnosis and screening. Early diagnosis strategies focus on providing timely access to cancer treatment by reducing or removing barriers to care and/or improving access to effective diagnosis services. Screening consists of testing women to identify cancers before any symptoms appear. Various methods have been evaluated as breast cancer screening tools, including mammography, clinical breast exam and breast self-exam ${ }^{1}$.

Since early detection is the key in effectively tackling breast cancer, it's important to assess the knowledge, attitude and practices towards breasts cancer. The reason for conducting this study among the health science and medical students was to ensure that, this group being future health care professionals, should possess adequate and accurate knowledge and attitude on breast cancer as well as BSE. They will provide health services and education to the public in the future. The aim of this study therefore, is to assess the knowledge, attitude and practices of breast cancer among health science students in Shahrekord city, Iran. 


\section{MATERIAL AND METHODS}

A cross- sectional study was conducted in 2017-2018 academic year among health science students and medical students in Shahrekord University of Medical Sciences. The sample size of the study was between 288 and 346 participants. The targeted sample size was obtained by calculating sample size base on sample size estimation for proportion in survey type of studies ${ }^{6}$. Assuming level of significance is 0.05 , power of $95 \%$, and anticipated population proportion of $25 \%$. Additional $20 \%$ subjects were added to allow adjustment of other factors such as withdrawals during the survey or missing data. Finally, a total sample size of 334 was reached.

The study sample was conveniently selected. A total of 334 students voluntarily participated in the study from department of nursing and midwifery, public health, radiology, laboratory and medicine. Participants were informed about the study and the questionnaires were administered to them. The questionnaires were collected immediately they completed filling them. About fifteen minutes was used to answer the questions.

Standard questionnaire was used in the data collection. The questionnaire was adopted from previous studies $7,8,9$. The English questionnaire was translated into Persian language and translated back into English. Before data collection begun, the questionnaire was pre-tested. Pre- test of questionnaire was done on thirty respondents who were chosen to ensure that the questions were clear to understand. The result of the pre-test was used to improve the phrasing of questions in the questionnaire. Questionnaire internal consistency tests showed that the Alpha Cronbach was 0.89 for knowledge, 0.91 for attitude and 0.96 for practice. The questionnaire consisted of four parts; sociodemographic characteristics of the respondents, breast cancer knowledge, attitude and about Breast Self-Examination (BSE) practices. Knowledge was assessed by asking about risk, protective factors and signs/symptoms of breast cancer.

The total score for these questions was 18. Correct answer attracted one mark while wrong answer and 'do not know' answer attracted zero. Any score more than 9 was considered as good knowledge and less was considered poor knowledge. Attitude was assessed by asking about future attitude if they will perform mammogram and clinical breast examination or not. Also, they were asked about their behaviour if they find lump in the breast whether they will be scared, go to prayer camp, go for traditional medicine, consult a doctor or agree to do mastectomy when required or not. The total score was 7. Those participants who answered "yes" scored 1 and "no" or "don't know" scored 0. Any score more than 4 was considered as good attitude and less than 4 as bad attitude?

Data was analysed using SPSS 24.0 program. Descriptive statistics were used to describe the study population and all the variables studied. Normality tests were conducted and all the quantitative data were not normally distributed. Pearson Chi-Square was used to test for association between categorical variables. Non Parametric test such as Mann-Whitney test was employed to determine differences between groups in terms of the BSE practice category and the knowledge score of risk factors, symptoms of breast cancer, and knowledge of BSE. The level of statistical significance was set at $a<0.05$. Ethical approval was obtained from Shahrekord University of Medical Sciences.

\section{RESULTS}

A total of 334 students participated in the study. The mean age of the respondents was $21.21 \pm 1.19$ years. Most of the respondents (61.7\%) aged 18 to 21 years. About $21 \%$ had family history of any types of cancers. Demographic data of the participants are shown in Table 1. About $99 \%$ of the respondents had heard about breast cancer. Most of them (97\%) stated education, internet, university and TV as their main source of information about breast cancer. None of them had done Mammogram or clinical breast examination by a specialist before.

The knowledge level was significantly different by age group $(P=0.002)$, department $(P=0.000)$ and those who attended training course $(P=0.000)$. Most of the medical faculty students had good knowledge $(91.4 \%)$ while more than half of the radiology students $(63.9 \%)$ had poor knowledge on breast cancer. Those who attended training course had good knowledge compared to those who didn't attend training course. People who ever attended a training course on prevention of breast cancer participated in the study (Table 2 ). 
Malaysian Journal of Public Health Medicine 2020, Vol. 20 (21): 178-184

Table 1. Socio-demographic Characteristics of the Respondents $(\mathrm{N}=334)$

\begin{tabular}{lll}
\hline Variable & Frequency & Percent (\%) \\
\hline Age Group & & \\
$18-21$ & 216 & 61.7 \\
$23-25$ & 118 & 38.3 \\
Department & 104 & 34.2 \\
Nursing and midwifery & 81 & 24.3 \\
Public Health & 36 & 10.85 \\
Radiology & 45 & 13.5 \\
Laboratory & 58 & 17.4 \\
Medicine & & \\
Family history of cancer & 21 & 6.3 \\
Yes & 313 & 93.7 \\
No & & \\
Attend any training course & 48 & 14.4 \\
Yes & 286 & 85.6 \\
No & & \\
Heard about cancer & 98.8 & 98.8 \\
Yes & 1.2 & 1.2 \\
No & & \\
\hline
\end{tabular}

Table 2. Relationship between Knowledge and Socio-demographic Characteristics of the Respondents $(\mathrm{N}=334)$

\begin{tabular}{|c|c|c|c|}
\hline \multirow[t]{2}{*}{ Variable } & \multicolumn{2}{|c|}{ Knowledge } & \multirow[t]{2}{*}{$\mathrm{p}$-value } \\
\hline & $\begin{array}{c}\text { Poor } \\
\text { No (\%) }\end{array}$ & $\begin{array}{c}\text { Good } \\
\text { No (\%) }\end{array}$ & \\
\hline \multicolumn{4}{|l|}{ Age group } \\
\hline $18-21$ & $118(57.3)$ & $88(42.7)$ & 0.002 \\
\hline $22-25$ & $51(39.8)$ & $77(60.2)$ & \\
\hline \multicolumn{4}{|l|}{ Department } \\
\hline Nursing and midwifery & $57(50.0)$ & $57(50.0)$ & \\
\hline Public Health & $42(51.8)$ & $39(48.2)$ & 0.000 \\
\hline Radiology & $23(63.9)$ & $13(36.1)$ & \\
\hline Laboratory & $42(93.3)$ & $3(6.7)$ & \\
\hline Medicine & $5(8.6)$ & $53(91.4)$ & \\
\hline \multicolumn{4}{|l|}{ Family history of cancer } \\
\hline Yes & $12(57.1)$ & $9(42.9)$ & 0.654 \\
\hline No & $157(50.2)$ & $156(49.8)$ & \\
\hline \multicolumn{4}{|c|}{ Attend any training course } \\
\hline Yes & $8(16.7)$ & $40(83.3)$ & \\
\hline No & $161(56.3)$ & $125(43.7)$ & 0.000 \\
\hline
\end{tabular}

The total possible knowledge score was 18.0. The overall mean knowledge score of breast cancer for participants was $9.31 \pm 3.44$. The range of score was 17 and median score was 9.0. The highest knowledge score was on symptoms and the lowest knowledge score was on the risk factors of breast cancer. Knowledge of signs and symptoms of breast cancer; majority of respondents recognized the following as signs and symptoms of breast cancer; pitting in the areola $(76.3 \%)$, bloody nipple discharge $(71.3 \%)$, breast lump (70.7\%), and armpit lump $(62.6 \%)$. However, few of the respondents recognized the following as signs and symptoms of breast cancer; change in breast size $(48.2 \%)$, and arm oedema (38.3\%). Knowledge about Risk Factors of Breast Cancer; majority of respondents recognized the following as risk factors of breast cancer; positive family history $(93.1 \%)$, using infertility drugs $(53.3 \%)$ and having the first child at older age (51.2\%). Only 9.3\% recognized irregular menstrual cycles as risk factors of breast cancer. Knowledge about protective factors of breast cancer among the respondents; $88.3 \%$ believed good nutrition and being physically active reduce the risk 
of Breast Cancer, 83.2\% recognized breast feeding protects against breast cancer and only $7.2 \%$ knew that late menstruation reduces the risk of Breast Cancer.

Mann-Whitney test was conducted to compare the mean knowledge of breast cancer for those who practice BSE and those who do not practice BSE. The results showed that there were significantly different in their knowledge score. Those who performed BSE had higher knowledge score about breast cancer than those who did not perform BSE (Table 3).

Table 3. Comparison of the Mean Knowledge of BC, BSE Score for Those Who Performed and Those Did Not $(n=334)$

\begin{tabular}{llllc}
\hline Variable & $\begin{array}{l}\text { Performing BSE } \\
(\mathrm{n}=119) \text { Mean(SD) }\end{array}$ & $\begin{array}{l}\text { Not Performing BSE } \\
(\mathrm{n}=215) \text { Mean(SD) }\end{array}$ & t-value & p-value \\
\hline Symptoms of Breast Cancer & $4.43 \pm 1.30$ & $3.25 \pm 1.74$ & 6.97 & $0.000^{*}$ \\
About Risk Factors & $3.27 \pm 1.14$ & $2.49 \pm 1.36$ & 5.06 & $0.000^{*}$ \\
About Protective Factors & $3.26 \pm 1.07$ & $2.65 \pm 1.35$ & 4.56 & $0.000^{*}$ \\
Overall Knowledge & $10.97 \pm 2.62$ & $8.40 \pm 3.50$ & 7.59 & $0.000^{*}$ \\
Attitude Statement & $4.15 \pm 1.03$ & $4.25 \pm 1.08$ & 0.83 & 0.545 \\
\hline
\end{tabular}

Overall, $44.3 \%$ of respondents had positive attitude towards breast cancer (Table 4). The participants' attitude was not significantly different by age

Table 4. Relationship between Attitude and Socio-demographic Characteristics of the Respondents $(\mathrm{N}=334)$ group, department, family history of cancer and attending of training courses $(p>0.05)$.

\begin{tabular}{llll}
\hline \multirow{2}{*}{ Variable } & \multicolumn{2}{c}{ Attitude } & \\
\cline { 2 - 3 } & $\begin{array}{l}\text { Negative } \\
\mathrm{N}(\%)\end{array}$ & $\begin{array}{l}\text { Positive } \\
\mathrm{N}(\%)\end{array}$ & \\
\hline Overall attitude & $186(55.7)$ & $148(44.3)$ & \\
Age group (in years) & & & \\
$18-21$ & $113(54.9)$ & $93(45.1)$ & 0.735 \\
$22-25$ & $73(57.0)$ & $55(43.0)$ & \\
Department & & & \\
Nursing and midwife & $60(52.6)$ & $54(47.4)$ & \\
Public Health & $45(55.6)$ & $36(44.4)$ & \\
Radiology & $25(69.4)$ & $11(30.6)$ & \\
Laboratory & $26(57.8)$ & $19(42.2)$ & \\
Medicine & $30(51.7)$ & $28(48.3)$ & \\
Family history of cancer & & & \\
Yes & $12(57.1)$ & $9(42.9)$ & \\
No & $174(55.6)$ & $139(44.4)$ & \\
Attend any training course & & & \\
Yes & $26(54.2)$ & $22(45.8)$ & \\
No & $160(55.9)$ & $126(44.1)$ & \\
\hline
\end{tabular}

Breast self-examination practice

Result obtained from this study showed that, the percentage of participants who performed breast self-examination (BSE) during the last year was 119 $(35.60 \%)$. Among those who practice BSE, most of them practice BSE always 65 (27.78\%), 6.6\% once in
3 months, $5.7 \%$ once in a month and $3.9 \%$ more than once in 3 months. The commonest reason given for not doing BSE was lack of knowledge on how to do it $175(83.4 \%)$ and fear of finding a lump 40 (18.6\%) (Table 5). 
Table 5. Relationship between Breast self-examination practice and Socio-demographic Characteristics of the Respondents $(\mathrm{N}=334)$

\begin{tabular}{llll}
\hline Variable & \multicolumn{2}{c}{ Practice } & P-value \\
\cline { 2 - 3 } & Yes & No \\
Age Group & N (\%) & & \\
$18-21$ & $60(29.1)$ & $146(70.9)$ & 0.002 \\
$22-25$ & $59(46.1)$ & $69(53.9)$ & \\
Department & & & \\
Nursing and midwifery & $48(42.1)$ & $66(57.9)$ & 0.000 \\
Public Health & $20(24.7)$ & $61(75.3)$ & \\
Radiology & $6(16.7)$ & $30(83.3)$ & \\
Laboratory & $6(13.3)$ & $39(86.7)$ & \\
Medicine & $39(67.2)$ & $19(32.8)$ & \\
Family history of cancer & & $15(71.4)$ & \\
Yes & $6(28.6)$ & $200(63.9)$ & \\
No & $113(36.1)$ & $10(20.8)$ & \\
Attend any training course & $38(79.2)$ & $205(71.7)$ & \\
Yes & $81(28.3)$ & & \\
No & & & \\
\hline
\end{tabular}

\section{DISCUSSION}

The study was carried out among health science and medical students to ensure that, this group being future health care professionals, should possess adequate and accurate knowledge and attitude on breast cancer as well as BSE. Findings show that only half of the participants had good knowledge. However, more than half of the participants had negative attitude towards breast cancer. The results of this study showed that almost all the participants (99\%) had heard of breast cancer. This is similar to the study finding by Samina et al (2018) on breast cancer awareness, attitude and screening practices among university students in Pakistan which showed that all the participants $(100 \%)$ had heard of breast cancer ${ }^{10}$. In this current study, respondents were asked on their source of information on breast cancer. Majority of them indicated education, internet, TV and university as their main source of information on breast cancer. This is similar to the finding by Khalid et al (2018) on Breast cancer among young girls: a KAP study conducted in Lahore which revealed that Internet, TV, breast cancer campaigns, friends and relatives and health professionals are their major source of information on breast cancer ${ }^{11}$.

Generally, on knowledge, almost half of the respondents (49.4\%) had good knowledge on breast cancer. This is similar to the study finding by Nur (2010) on Breast Cancer Knowledge and Screening Behaviors of the Female Teachers in Turkey which showed that about half of the respondents $(52.4 \%)$ believed to have adequate knowledge on Breast cancer ${ }^{12}$. Another study reported that the prevalence of good knowledge was $45.2 \%$ among male students in Malaysia 13 Majority of the respondents in this study had high knowledge on these signs and symptoms; pitting of the areola (76.3\%), bloody nipple discharge $(71.3 \%)$, breast lump (70.7\%), and armpit lump (62.6\%). This finding is in line with the study finding by Sathian et al (2014) on awareness of breast cancer warning signs and screening methods among female residents of Pokhara Valley, Nepal which revealed that most participants indicated breast lump, bloody discharge from nipple, armpit lump, pulling of the nipples and others as the main symptoms of breast cancer ${ }^{14}$. Also, majority of the respondents indicated positive family history (93.1\%), use of infertility drugs (53.3\%) and having the first child at older age (51.2\%) as the risk factors for breast cancer. This study finding contradicts the finding by Santhanakrishnan et al (2016) on knowledge, attitude, and practice regarding breast cancer and its screening methods among nursing staff working in a tertiary-care hospital located in South India which revealed that most participants indicated inadequate breastfeeding, radiation exposure, and genetic factors as the risk factors for breast cancer. It is however in line with the finding that family history is a major risk factor in developing breast cancer ${ }^{15}$. In addition, only $35.6 \%$ performed BSE. Among those who performed BSE, $27.78 \%$ always performed it, $6.6 \%$ performed once in three months, $5.7 \%$ performed once in a month and $3.9 \%$ performed more than once in three months. This finding is similar to the study finding by Sayed et al (2016) on knowledge, attitude and practice of breast cancer screening methods among women in the north of Iran which showed that $46 \%$ performed 
BSE and $14.3 \%$ performed it monthly ${ }^{16}$. The finding is also similar to the study finding by Samina et al (2018) on breast cancer awareness, attitude and screening practices among university students in Pakistan which showed that only $23 \%$ of the respondents practiced BSE ${ }^{10}$. The current study finding however contradicts the finding by Sarfo et al (2013) on knowledge, attitude, and practice of self-breast examination among female university students at Presbyterian University College, Ghana which revealed that $60 \%$ performed BSE ${ }^{17}$. The current study also contradicts the study by Andegiorgish et al (2018) on Knowledge, attitude, and practice of breast cancer among nurses in hospitals in Asmara, Eritrea which revealed that $75.5 \%$ practiced BSE. Out of this, $60 \%$ practiced monthly, $7.2 \%$ practiced once every three months, and $14.5 \%$ practiced once a year ${ }^{18}$.

In this study, some respondents indicated they do not perform BSE for various reasons. These are; lack of knowledge on how to do it (83.4\%) and fear of finding a lump (18.6\%). This study finding is similar to the finding by Alwan et al (2012) on knowledge, attitude and practice regarding breast cancer and breast self-examination among a sample of educated population in Iraq which revealed that majority of the them indicated fear of finding lump and lack of knowledge on how to do it as the main reasons for not performing BSE ${ }^{19}$. Furthermore, none of the respondents in this current study had done Mammogram or clinical breast examination by a specialist before. This finding is similar to the finding by Elsie et al (2010) on current knowledge, attitudes and practices of women on breast cancer and mammography at Mulago Hospital in Uganda which revealed that none of the respondents had done mammogram before ${ }^{20}$. The study was a crosssectional survey using self-administered questionnaires. Information bias may occur since the questionnaires may generate biased and preconceived answers. The results of this study should not be generalized to all health science and medical students due to the sampling technique and single study centre.

\section{CONCLUSION}

The study revealed that about half of the respondents (49.4\%) had good knowledge on breast cancer. The good knowledge on breast cancer was mostly on signs and symptoms with some on risk factors and protective factors. The study also showed that participants had poor attitude and practice towards breast cancer screening. Less than half of the respondents (35.6\%) perform BSE and none of them have ever done CBE and mammogram. There is therefore the need to increase education on breast cancer to students in Iran since most participants' knowledge, attitude and practice towards breast cancer is not satisfactory. The university should give adequate lectures and seminars related to topic to students.

Conflict Interest: There is no conflict interest

Acknowledgment: We would like to thank all the participants.

Author Contributions: Conceptualization: NM, ML. Data collection: ML, AR. Formal analysis: NM, AR. Methodology: NM, ML, AR, AD. Writing - original draft: $N M, A D$ Writing - review \& editing: $N M, A D$, $M L, A R$

\section{REFERENCES}

1. World Health Organisation. Breast cancer. https://www.who.int/cancer/prevention/dia gnosis-screening/breast-cancer/en/. Accessed on 16th March, 2019

2. Parkin DM, Bray F, Ferlay J, Pisani P. Global cancer statistics, 2002. CA Cancer J Clin. 2005;55(2):74-108. doi:10.3322/canjclin.55.2.74

3. Haghighat S, Akbari ME, Ghaffari S, Yavari P. Standardized breast cancer mortality rate compared to the general female population of Iran. Asian Pac J Cancer Prev. 2012;13(11):5525-5528. doi:10.7314/apjcp.2012.13.11.5525

4. Taghavi A, Fazeli Z, Vahedi M, et al. Increased trend of breast cancer mortality in Iran. Asian Pac J Cancer Prev. 2012;13(1):367-370. doi:10.7314/apjcp.2012.13.1.367

5. Sharifian A, Pourhoseingholi MA, Emadedin M, et al. Burden of Breast Cancer in Iranian Women is Increasing. Asian Pac J Cancer Prev. 2015;16(12):5049-5052. doi:10.7314/apjcp.2015.16.12.5049.

6. Wunsch D. Survey research. Determining sample size and representative response. Business education form 1985;40(5): p1\&25.

7. Salati SA, Rather A. Awareness regarding female breast cancer in Kashmiri males. Online J Health Allied Scs 2009, 8, 11.

8. Okobia, M.N., Bunker, C.H., Okonofua, F.E. et al. Knowledge, attitude and practice of Nigerian women towards breast cancer: A cross-sectional study. World J Surg Onc 4, 11 (2006). https://doi.org/10.1186/1477-78194-11 
9. Hasan TN, Shah SA, Hassan MR, et al. Poor Knowledge and Practice Towards Breast Cancer among Women in Baghdad City, Iraq. Asian Pac J Cancer Prev. 2015;16(15):6669-6672.

doi:10.7314/apjcp.2015.16.15.6669

10. Samina R, Zainab W, Fatima S. Breast Cancer Awareness, Attitude and Screening Practices Among University Students: Intervention Needed. Biomed J Sci \&Tech Res 4(5)- 2018. DOI: 10.26717/ BJSTR.2018.04.001100.

11. Khalid A, Hassnain S, Gakhar H, Khalid B, Zulfiqar F, Wahaj A. Breast cancer among young girls: KAP study conducted in Lahore. International Journal of Scientific Report. 2018;4(6):166-171. DOI: http://dx.doi.org/10.18203/issn.24542156.IntJSciRep20182206

12. Nur N. Breast Cancer Knowledge and Screening Behaviors of the Female Teachers. Women \& Health, 2010; 50:1, 37-52, DOI: $10.1080 / 03630241003601087$

13. Ghazi, Hasanain Faisal, Maged Elnajeh, Afifah Azri, Mohammed A. Abdalqader, Mohammad Faez and Al-abed Ali Ahmed Al-abed. Knowledge and Beliefs On Female Breast Cancer Among Male Students in A Private University, Malaysia. Malaysian Journal of Public Health Medicine, 2017;17(1):8-13.

14. Sathian B, Nagaraja SB, Banerjee I, Sreedharan J, De A, Roy B, Rajesh E, Senthilkumaran S, Hussain SA, Menezes RG. Awareness of Breast Cancer Warning Signs and Screening Methods among Female Residents of Pokhara Valley, Nepal. Asian Pac J Cancer Prev, 2015 (11), 4723-4726

15. Santhanakrishnan N, Prabakaran S, Singh Z. Knowledge, attitude, and practice regarding breast cancer and its screening methods among nursing staff working in a tertiary-care hospital located in South India. International Journal of Medical Science and Public Health 2016; 5:1650-1655. doi: 10.5455/ijmsph.2016.06122015275

16. Seyed AN, Sara D, Davood S, Ali M. Knowledge, Attitude, and Practice on Breast Cancer Screening Methods among Women in the North of Iran. International Journal of Humanities and Cultural Studies, 2016; ISSN 2356-5926.

17. Linda Akuamoah Sarfo, Dorothy AwuahPeasah, Elizabeth Acheampong, Florence Asamoah. Knowledge, attitude, and practice of self-breast examination among female university students at Presbyterian University College, Ghana. American Journal of Research Communication, 2013, 1(11): 395-404\} ISSN: 2325-4076.

18. Andegiorgish AK, Kidane EA, Gebrezgi MT. Knowledge, Attitude, and Practice of Breast Cancer among Nurses in Hospitals in Asmara, Eritrea. BMC Nursing 2018; 17:33 https: / /doi.org/10.1186/s12912-018-0300-4

19. Alwan NAS, Al-Attar WM, Eliessa RA, Madfai ZA , Tawfeeq FN. Knowledge, attitude and practice regarding breast cancer and breast self-examination among a sample of the educated population in Iraq. Eastern Mediterranean Health Journal 2012; 18:4

20. Elsie KM, Gonzaga MA, Francis B, et al. Current knowledge, attitudes and practices of women on breast cancer and mammography at Mulago Hospital. Pan Afr Med J. 2010; 5:9. Published 2010 May 6. doi:10.4314/pamj. v5i1.56186 